\title{
O conceito de lexicultura e suas implicações para o ensino-aprendizagem de português língua estrangeira
}

\author{
Lúcia Maria de Assunção Barbosa*
}

RESUMO: A partir do pressuposto da indissociabilidade entre as dimensões linguísticas e culturais no ensino-aprendizagem de línguas, propõe-se a associação entre léxico e cultura como um modo de garantir o acesso do aprendente à cultura implícita no cotidiano de uma língua estrangeira. Este artigo pretende discutir os conceitos de lexicultura e de palavras com carga cultural compartilhada a fim de mostrar sua pertinência no contexto de ensino-aprendizagem de língua estrangeira em geral e de português língua estrangeira, em particular.

PALAVRAS-CHAVE: Léxico; lexicultura; carga cultural compartilhada; língua estrangeira; cultura; Português Língua Estrangeira.

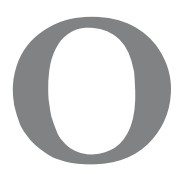

léxico possui um papel importante para a emissão e para a compreensão de significados, pois está diretamente ligado aos aspectos cognitivos, sociais e culturais de uma língua.

De acordo com os princípios de E. Sapir, as palavras são uma forma privilegiada de acesso a uma cultura, uma vez que elas são portadoras de concepções ou de visões de mundo. Desse modo, as características específicas de cada língua podem ser consideradas o reflexo da identidade cultural da sociedade. A esse respeito, Biderman (2001) afirma que, após a chamada hipótese de E. Sapir, todo sistema lingüístico manifesta, tanto no léxico quanto na gramática, uma classificação específica de fatos culturais, ou seja: "uma classificação e uma ordenação dos dados da realidade que são típicas dessa língua e dessa cultura com que ela se conjuga".

* Universidade Federal de São Carlos - lubarbo@ufscar.br. 
Em seus estudos sobre o léxico, Matoré (1953) assinala o fato de que a palavra é um instrumento de compreensão social, pois funciona como símbolos com os quais agimos sobre nossas idéias. Nesse sentido, o léxico nos auxilia a compreender e a explicar a sociedade da qual fazemos parte ou à qual pretendemos ou queremos aceder. Sob essa perspectiva, a lexicologia está, segundo o autor, muito próxima da sociologia, pois o estudo desses dois domínios incide sobre fatos sociais. O que os distingue é o fato de que a lexicologia parte do estudo do vocabulário para explicar uma sociedade, ou seja, ela é uma disciplina sociológica que utiliza, como material lingüístico, as palavras:

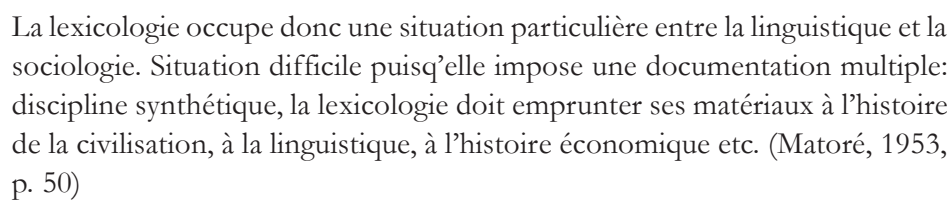
sociologie. Situation difficile puisq'elle impose une documentation multiple: discipline synthétique, la lexicologie doit emprunter ses matériaux à l'histoire de la civilisation, à la linguistique, à l'histoire économique etc. (Matoré, 1953, p. 50)

No que se refere ao contexto de ensino-aprendizagem de uma língua estrangeira, o conhecimento lexical mostra-se de extrema relevância no processo de comunicação, pois, conforme assinala Biderman (1998, p. 73):

[...] a referência à realidade extralingüística nos discursos humanos faz-se através dos signos lingüísticos, ou unidades lexicais, que designam os elementos desse universo segundo o recorte feito pela língua e pela cultura correlatas. Assim, o léxico é o lugar da estocagem da significação e dos conteúdos significantes da linguagem humana.

Dentre as proposições que faz a respeito das dimensões culturais no contexto de ensino de língua estrangeira, Beacco (2000, p. 96) apóia-se no fato de que em uma mesma nação coabitam grupos diferentes e, por isso, no processo de ensino-aprendizagem, o léxico pode ser tomado como uma das formas de se estabelecer uma associação entre os binômios língua-cultura. De acordo com o mesmo autor, se cada língua organiza uma visão do mundo por meio de um recorte lexical, a compreensão de seus dados culturais implica saber reconhecer nas palavras dessa língua as crenças, as regras de conduta e a organização social, pois são esses elementos que evidenciam concepções do mundo das quais os membros dessa sociedade compartilham.

Nessa perspectiva, o acesso a um conjunto lexical, diferente daquele a qual está habituado, requer de um aprendente de língua estrangeira esforços que lhe permitam integrar novos conhecimentos lingüístico-culturais, a fim de compreender valores, crenças usos e costumes, em um constante movimento de convergências e de divergências com sua própria cultura. 


\section{A lexicultura: a cultura do cotidiano no e pelo léxico}

Se levarmos em conta que o léxico não é transparente e nem unívoco, mas opaco e polissêmico, o seu uso mostra, aos poucos, ao aprendente de uma língua estrangeira, as possibilidades de utilização de uma mesma palavra, por exemplo, no sentido denotativo ou conotativo. Nessa mesma perspectiva, é possível apreender que há palavras mais carregadas de referências culturais que outras, cuja significação nem sempre é acessível a falantes de outras línguas.

A respeito desse conjunto de palavras, Robert Galisson (1987) propõenos o conceito de lexicultura, enquanto um modo de acesso ao estudo do léxico culturalmente marcado. Entre outros aspectos, a lexicultura mostranos a singularidade e a diversidade dos lugares onde a cultura pode ser encontrada em uma língua, pois, sabemos que o léxico é o nível de descrição lingüística mais diretamente ligado à realidade extralingüística.

De acordo com Guillén Díaz (2003), o termo - resultado da união das duas formas léxico e cultura - evoca duas conotações: uma, referente ao léxico, que nos reenvia à palavra, ao conjunto de palavras que uma língua comporta; outra, relativa à cultura, que está ligada ao conjunto de manifestações por meio das quais se expressa o cotidiano de um povo.

A partir dessa composição, o conceito de lexicultura privilegia a consubstancialidade do léxico e da cultura e designa o valor que as palavras adquirem pelo uso que se faz delas. Valor esse, que, segundo Galisson (1995), tem sido pouco assegurado pelos dicionários. O objeto de estudo da lexicultura é assim apresentado pelo autor:

\footnotetext{
La culture en dêpot dans ou sous certains mots, dits culturels, qu'il convient de repérer, d'expliciter et d'interpréter. La démarche consiste à mettre au jour des sites culturels [...]. Les expressiosn imagées, les mots-valises, les mots à charge culturellle partagée, les palimpsestes verbo-culturels, les mots de situations, les noms de marques, les proverbes et dictons, les mots ocultants [...] circonscrivent les sites (ou gisements). (Galisson, 1999, p. 480)
}

No campo da lexicografia contemporânea e da lexicografia de aprendizagem da língua materna e estrangeira, Lino (2003, p. 20) ressalta a importância desse conceito tanto no seu nível teórico quanto no metodológico, uma vez que ele permite, por exemplo, colocar em destaque as palavras, os provérbios, os ditados e expressões imagéticas com conteúdos culturais compartilhados entre os membros de uma mesma comunidade lingüística.

Trata-se, portanto, do estudo da cultura em qualquer discurso cujo objetivo não seja o de estudar a cultura por si mesma, pois, ao invés de isolar a 
cultura do seu meio natural, o autor propõe sua preservação no interior da sua própria dinâmica. O ponto de partida será o discurso do cotidiano e, por conseguinte, a proposta é de uma abordagem discursiva que integra, associa e não separa os componentes da comunicação, no interior de um processo de abertura e de complementaridade.

A lexicultura reenvia, segundo R. Galisson (1997), a uma representação mental mais elaborada e construída tomando como ponto de partida a análise de um inventário de objetos pertencentes a uma mesma categoria.

Dada a sua vocação voltada para a prática (e menos para a teoria), a lexicultura é um conceito instrumental. Ao possuir, na sua concepção a cultura no e pelo léxico, ela faz de seu objeto de estudo um elemento para ação e para a intervenção, disponibilizando essa cultura ao alcance do aprendente de uma língua estrangeira.

\section{Palavras com carga cultural compartilhada}

Ao léxico marcado pela carga cultural, Galisson (1987) dá o nome de palavra com carga cultural compartilhada ${ }^{1}$ (CCC). Trata-se do valor acrescentado ao sentido referencial da palavra, que é conhecido e compartilhado entre os membros pertencentes a uma cultura e constitui fator de aproximação e de reconhecimento mútuo. A carga cultural compartilhada está mais próxima da cultura da experiência, da vivência e do cotidiano e mais distante da chamada cultura erudita, cultivada ou institucional. Para o autor, a diferença fundamental entre cultura cotidiana e cultura erudita é que a primeira aprende-se na prática social e condiciona o que há de essencial em nossos comportamentos. Vista dessa perspectiva, a cultura cotidiana é quase imperceptível para falantes nativos, razão pela qual esse tipo de cultura não ter sido alvo de descrições. A cultura erudita, por sua vez, está presente nos livros e nos currículos escolares e, desse modo, pode ser ensinada tanto a falantes nativos quanto a falantes não-nativos.

Esse conceito mostra-se relevante para o contexto de ensino-aprendizagem de língua, desde que se parta de uma compreensão de que os aspectos linguísticos e culturais de uma língua são dimensões que não podem estar dissociadas. Além disso, para o aprendente, a apreensão da carga cultural compartilhada mostra-se como um instrumento auxiliar para uma compreensão

1 Optamos por traduzir como carga cultural compartilhada a expressão charge culturelle partagéeCCP - em lugar de carga cultural partilhada. 
da fisionomia da palavra, ${ }^{2}$ ou seja, para o sentido cultural do qual a palavra está carregada num dado enunciado. A carga cultural compartilhada apresenta-se como um modo de adentrar à cultura do outro a fim de entender e fazer-se entender para além das aparências: no nível dos implícitos culturais de que a língua é portadora.

\section{Carga cultural compartilhada e implícitos culturais no ensino-aprendizagem de língua estrangeira}

O conteúdo da carga cultural compartilhada (ou CCP) apresenta-se sob o formato de significante do signo, o que lhe garante autonomia. Isso quer dizer que algumas palavras são mais moblizadas pela sua CCP do que pelo seu significado. Ela se distingue deste porque ela é compartilhada, o que lhe dá o status de pertencer ao patrimônio coletivo, pois advém de um denominador cultural comum aos indivíduos de um dado grupo social.

Galisson (1994) define a CCP como um valor de complemento, mobilizável pela grande maioria de locutores de um grupo social, os quais a reconhecem pela simples evocação do signo com o qual ela mantém relações estruturais de solidariedade (o signo fornece um significado a quem ela empresta um complemento).

A carga cultural compartilhada pode apresentar-se, segundo Galisson (1991 e 1987), sob a forma de (a) estereótipos representados por certas locuções cristalizadas, associando animais a defeitos ou qualidades humanas ou locuções que comparam o ser humano ao animal; incluindo aqui os chamados inanimados culturais (objetos fabricados ou não pelo homem aos quais são creditadas cargas que qualquer falante nativo mobiliza ao entrar em contato auditivo ou visual - da palavra que se refere ao objeto); (b) associação de um lugar a um produto ou vice-versa; (c) costumes, crenças, superstições e comportamentos evocados pela palavra.

Podemos reconhecer a carga cultural compartilhada de uma palavra a partir das seguintes características:

- ela é um conteúdo que tem por forma o significante do signo;

- é obrigatoriamente partilhada (pelo conjunto do grupo social);

- é produto da relação entre o signo e os seus utilizadores;

2 Expressão utilizada por Maddalena De Carlo, L'interculturel. Paris: CLE International, 1998, p. 104. 
- procede da subjetividade dos locutores coletivos, os quais interpretam um elemento a partir da sua visão de mundo;

- pertence ao domínio da pragmática, pois está vinculada ao uso que se faz dela;

- fornece um complemento, um conteúdo, um significado ao signo com o qual mantém uma relação estrutural de solidariedade;

- resulta de uma associação automática entre o signo e sua C.C.P., bastando uma simples evocação desse signo.

Portanto, evidencia-se que o estudo da lexicultura tem como foco não o significado da expressão ou da palavra em si - tarefa empreendida pelos dicionários - mas o dado cultural - coletivo - evocado pelo signo, uma vez que ele vai revelar as escolhas feitas por aquela coletividade.

Transparência e opacidade em palavras, expressões e imagens com carga cultural compartilhada: o exemplo de medida do Bonfim

As letras de canções, por estarem entre os chamados textos sociais (Benadava, 1982), são fontes de conhecimentos e de cumplicidades culturais vivenciados pela comunidade de locutores nativos. No Brasil, a canção tem uma presença expressiva no cotidiano da sociedade e pode, de acordo com Barbosa (2005), ser considerada um elemento revelador de aspectos linguísticos e culturais do país. Dado que ela está inserida no imaginário coletivo e transita livremente em todas as camadas sociais, ela é portadora de palavras e expressões com cargas culturais compartilhadas entre a coletividade.

Nesse sentido e no contexto do ensino aprendizagem de Português Língua estrangeira, na sua versão brasileira, tomemos o seguinte trecho da canção de Chico Buarque:

Eu vou lhe deixar a medida do Bonfim

Não me valeu.

(Hollanda, 1989, p. 173).

O verbete medida, registrado no dicionário Houaiss, ${ }^{3}$ contempla a expressão medida do Bonfim. O significado dessa expressão seria apreendido com facilidade por um número significativo de falantes nativos ou daqueles que

Consultamos as versões Aurélio (1999) e Houaiss (2001). 
conhecem a língua portuguesa, na sua versão brasileira. Nesse caso, não haveria necessidade de se buscar ajuda no dicionário, pois, de acordo com o contexto apresentado, a identificação do sentido da carga cultural compartilhada da palavra não seria um obstáculo. Desse modo, a expressão medida do Bonfim seria tomada como referência à crença popular, segundo a qual o uso dessa fita, além de trazer sorte, pode desencadear a concretização de três desejos. Para isso, de acordo com a crença, basta fazer três nós e, ao mesmo tempo, pensar nos três desejos. Nesses versos do cantor e compositor Chico Buarque de Hollanda, o enunciador devolve a fita, cujos efeitos (trazer sorte, e dar proteção) não foram sentidos por ele (não me valeu).

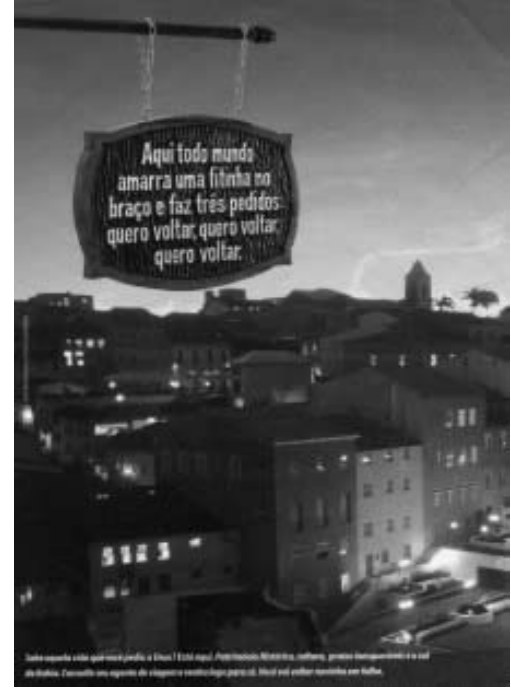

Fonte: Revista Veja (12-12-2001, p. 124-125) Figura 1
A expressão medida do Bonfim nasce na cidade de Salvador (Bahia), a partir da festa de Nosso Senhor do Bonfim, que ocorre todos os anos em frente à Igreja construída, entre os anos de 1740 e 1754, em homenagem ao santo. Reconhecida como uma festa de devoção sincrética, ela reúne católicos e praticantes do candomblé e é celebrada logo após o Dia de Reis (6 de janeiro). Nessa ocasião, cerca de cem baianas vestem-se de branco e - ao som de atabaques, palmas e cânticos africanos - fazem a lavagem das escadarias e do adro da igreja com água de flores. No interior da igreja, há a chamada sala de ex-votos onde ficam registradas as mais diversas formas de expressão da fé de milhares de peregrinos que por lá estiveram agradecendo as graças alcançadas. A tradição, sagrada entre os devotos do santo, ensina que se deve amarrar a fitinha (medida de Nosso Senhor do Bonfim) no pulso, com três nós, repetindo em cada um deles um pedido.

Entretanto, toda esta rede de significados seria opaca para falantes de outras línguas que desconhecessem a carga cultural compartilhada dessa expressão (sorte, proteção), ainda que se recorresse ao dicionário. A esse respeito, Galisson (1997) diz que o dicionário possui papel fundamental para o tratamento da lexicultura, pois ele possibilita ao aprendente não para o tratamento da lexicultura, pois ele possibilita ao aprendente não
apenas o conhecimento da cultura do outro, mas uma reflexão acerca de sua própria cultura, relacionando-a com a que está sendo aprendida e reconhecendo as diferenças entre elas.

A medida do Bonfim tornou-se símbolo não apenas religioso, mas também turístico do Estado da Bahia. A sua carga cultural - sorte e proteção - é retomada em diferentes situações e publicidades conforme ilustramos no exemplo da figura 1 :

Como podemos observar, essa publicidade da Secretaria de Turismo da Bahia retoma a fita como símbolo daquele Estado. Com a frase "Aqui todo mundo amarra uma fitinha no braço e faz três pedidos: quero voltar, quero voltar, quero voltar", faz uma brincadeira com a crença relacionada aos três nós da fitinha com o objetivo de chamar o turista para voltar a visitar a Bahia. Neste caso, é a palavra fitinha que remete à crença compartilhada. Para um falante de outra língua, essa palavra seria completamente opaca, ainda que ele consultasse um dicionário. 

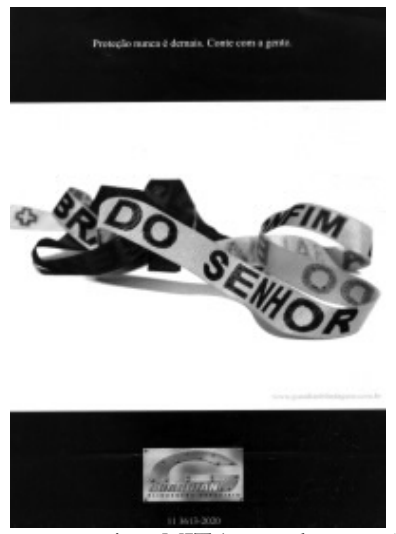

Fonte: Revista $M I T$ (n. 20, dez. 2005, p. 103)

Embora a carga cultural compartilhada esteja ligada à palavra (que se lê ou que se ouve), há casos em que a imagem de um objeto evoca automaticamente a palavra e, conseqüentemente, a carga cultural que ela detém. A imagem publicitária da figura 2 constitui um exemplo bem-sucedido desse aspecto.

Trata-se de uma publicidade de uma empresa de segurança que utiliza a imagem da medida do Bonfim, fabricada de um outro material mais forte, a fim de indicar proteção e segurança oferecidos pela empresa. Nesse caso, observamos a retomada da carga cultural que esse objeto comporta entre grande parte da sociedade brasileira ou para falantes de outras línguas que tenham apreendido a crença que envolve o significado implícito nessa fita. Em se tratando de um aprendente de português em nível inicial ou básico, os significados desta publicidade seriam pouco ou nada transparentes.

Figura 2

$\mathrm{Na}$ imagem da figura 3 a seguir, o grau de opacidade de fita parece apresentar-se com menos intensidade, embora outros fatores contribuam para uma compreensão parcial da carga compartilhada.

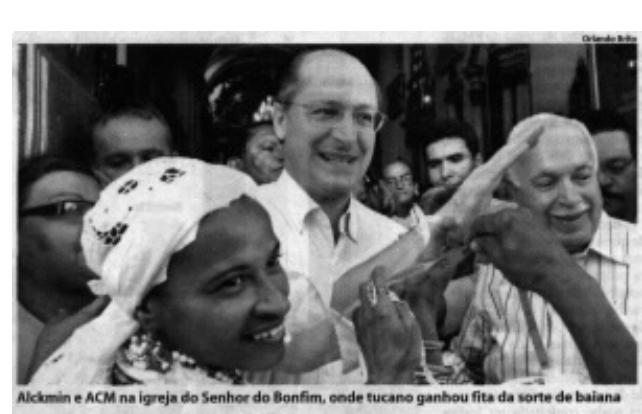

Fonte: Folha de S. Paulo (13/05/2006, p. A-6)

Figura 3

Neste caso, o fato de a palavra fita estar seguida do complemento da sorte fornece indicações de seu significado, porém, ainda assim, a carga cultural compartilhada não se revela completamente para um falante de outra língua, uma vez que o mesmo não apreenderia nesse enunciado a representação desse ato da baiana. Acrescente-se a isso, o fato de que a cena se passa na igreja do Senhor do Bonfim, local pleno de significados, conforme vimos. Há, ainda, todo um contexto em torno das figuras políticas presentes na foto: o paulista Geraldo Alckmin era candidato à presidência da República e estava acompanhado pela figura emblemática do Senador baiano Antonio Carlos Magalhães (popularmente conhecido como $A C M)$. Portanto, o significado da expressão fita da sorte está atrelado ao reconhecimento prévio desses outros elementos contextuais.

A partir desses exemplos, constatamos que o uso da carga cultural compartilhada constitui uma marca fundamental, embora discreta e inconsciente, de pertencimento ao grupo. Quando tudo parece evidente, o fator cultural aparece na sua relatividade, por meio de convenções reconhecidas pela comunidade. Dessa maneira, a carga cultural compartilhada é o produto da relação que rege o signo e aqueles que a utilizam. Sob essa perspectiva, de acordo com Galisson (1999), ela está mais próxima da pragmática e da antropologia cultural. Além desse aspecto, a lexicultura também privilegia os chamados implíci- 
tos culturais de uma língua, discutidos por Zarate (1986), que são, segundo a autora, os fatos que circulam por trás da insignificância aparente das interações sociais, da rotina e da trivialidade do cotidiano, caracterizando-se como signo de uma experiência muda do mundo.

No contexto de ensino-aprendizagem de uma língua-cultura estrangeira, a inserção de atividades pedagógicas que priorizem palavras com carga cultural compartilhada é de indiscutível pertinência, pois, como vimos, elas compreendem os costumes, o comportamento, a tradição, a superstição e as crenças evocadas pela palavra. Dessa perspectiva, essas palavras podem impor fronteiras de compreensão àqueles que não compartilham desses mesmos saberes, ou seja, o grau de conhecimento desses implícitos culturais pode ser determinante para uma inserção (ou exclusão) de um falante de outra língua.

No caso das palavras com cargas culturais compartilhadas, podemos dizer que os implícitos culturais exercem uma função identitária sobre o signo porque agem como facilitadores da compreensão recíproca entre os falantes de língua materna. Seu funcionamento é marcado por um uma espécie de consenso social, por meio do qual os membros de uma sociedade se reconhecem e podem ser reconhecidos. Dessa maneira, os implícitos culturais e o léxico culturalmente marcado apóiam-se nas experiências, nos feitos, nos ditos e reproduzem saberes de eficácia já comprovada. Ambos podem ser igualmente entendidos como traços de uma memória coletiva que assinala no presente a arqueologia de nossas práticas sociais (Zarate, op. cit.).

\section{Conclusão}

Vimos que o conceito de lexicultura proposto por R. Galisson constitui um instrumento que torna perceptível a cultura no e pelo léxico. O léxico passa a ser, assim, abordado como um locus privilegiado não apenas para o conhecimento, mas para o reconhecimento de significados culturais presentes em unidades lexicais culturalmente compartilhadas entre locutores nativos, mas que nem sempre se mostram transparentes para falantes de outras línguas, pertencentes a outras culturas.

No nosso entendimento, esse instrumento ajuda-nos a perceber que a língua não pode ser vista como uma estrutura que independe dos seus usuários. Ela confunde-se com a cultura daqueles que a utilizam. Sob esse ponto de vista, as palavras funcionam como receptores de conteúdos culturais que nelas se aderem e a elas agregam outra dimensão para além daquelas apresentadas nos dicionários. 
No que concerne às implicações didático-pedagógicas no ensino e na aprendizagem de uma língua estrangeira, as palavras com cargas culturais compartilhadas ensejam um procedimento intercultural, tal qual propõe Galisson (1994), tanto no que concerne à edição de dicionários com essa via cultural quanto na inclusão desse conteúdo nos materiais didáticos de língua estrangeira.

A partir dessa ótica, a língua passa a ser considerada não mais como um instrumento para a comunicação, mas como um depositário da cultura da qual ela é representante. Essa aliança entre língua e cultura vincula o ensinoaprendizagem de uma língua estrangeira às experiências significativas vividas e adquiridas no cotidiano, levando em consideração as interações sociais a que um aprendente é exposto, sobretudo quando se está em situação de imersão.

\section{Bibliografia}

BARBOSA, L. M. de A. (2005) Opacité et transparence léxico-culturelle dans l'apprentissage du portugais langue etrangère au Brésil: Les paroles de chansons, instruments de médiation linguistique et culturelle. Paris. Tese (Doutorado em Letras) - Université Paris VIII.

BEACCO, J-C. (2000) Les dimensions culturelles des enseignements de langue: Des mots au discours. Paris: Hachette.

BENADAVA, S. (1982) De la civilisation à l'ethno-communication, Les voies de la communication interculturelle. In: ZARATE, G. Le Français dans le Monde, 170, p. 33-48.

BIDERMAN, M. T. C. (2001) Teoria Lingüistica: teoria lexical e lingüística computacional. São Paulo: Martins Fontes.

. (1998) O vocabulário fundamental no ensino do Português como segunda língua. In: SILVEIRA, R. C. P. da. Português Lingua Estrangeira: perspectivas. São Paulo: Cortez. p. 73-91. DE CARLO, M. (1998) L'interculturel. Paris: CLE International.

GALISSON, R. (1987) Accéder à la culture partagée par l'entremise des mots à CCP. Études de Linguistique Apliquée, 67, p. 109-151.

. (1989) La culture partagée: une monnaie d'échange interculturelle. Le Français dans le Monde - Recherches et Application, p. 113-117. Lexiques - Numéro spécial - s/nº

- (1991) De la langue à la culture par les mots. Paris: CLE International.

$15-26$.

(1994) D’hier à demain, l'interculturel à l'école. Études de Linguistique Apliquée, 94, p.

. (1995a) En matière de culture le ticket AC - DI a-t-il un avenir. Études de Linguistique Apliquée, 100, p. 79-97.

(1995b) Où il est question de lexiculture, de Cheval de Troie et d'impressionnisme. Études de Linguistique Apliquée, 97, p. 5-14.

(1997) Un dictionnaire à géométrie variable au service de la lexiculture. Cabiers de lexicologie, 70/1, p. 57-77. 
GUILLÉN DÍAZ, C. (2003) La lexiculture: d'un concept instrumental à un outil d'intervention en didactique des langues. In: LINO, M. T ; PRUVOST, J. (Org.) Mots et lexiculture. Paris: Honoré Champion. p. 33-50.

LINO, M. T. (2003) Preface. In: LINO, M., PRUVOST, J. (Org.) Mots et lexiculture. Paris: Honoré Champion. p. 19-29.

MATORÉ, G. (1953) La méthode en lexicologie. Domaine français. Paris: Didier.

ZARATE, G. (1986) Enseigner une culture étrangère. Paris: Hachette.

ABSTRACT: From the presupposition of indissociability between linguistic and cultural aspects in the teaching-learning language process, an approximation between lexis and culture as a way of ensuring the access of the learner to culture implicit in the daily life of a foreign language is proposed. The aim of this article is to discuss concepts of lexiculture and words having a shared cultural content created by Robert Galisson. The article also shows its relevance in the context of the teaching-learning process of a foreign language in general and of portuguese as a foreign language, particularly brazilian Portuguese.

KEYWORDS: Lexis; lexiculture; shared cultural content; Foreign Language; culture; Portuguese as a Foreign Language. 